\title{
$\angle S$ Research Square \\ Non- Specific Low Back Pain among Nurses in Qassim, Saudi Arabia: A Cross-Sectional Study
}

Abeer Abuzeid Atta Elmannan ( $\square$ abeeralmannan@qumed.edu.sa )

Qassim University https://orcid.org/0000-0001-7840-8047

Hajar A. AlHindi

Qassim University

Reema I. AlBaltan

Qassim University

Mariah S. AlSaif

Qassim University

Nouf S. AlMazyad

Qassim University

Ruba K. AlZurayer

Qassim University

Shouq S. AlRumayh

Qassim University

Research article

Keywords: Low back pain, Prevalence, Risk factors, Qassim, Saudi Arabia

Posted Date: September 1st, 2020

DOI: https://doi.org/10.21203/rs.3.rs-59629/v1

License: (c) (i) This work is licensed under a Creative Commons Attribution 4.0 International License.

Read Full License 


\section{Abstract}

Background: Non-specific Low back pain (LBP) is a complex and multifactorial health problem. Evidence has shown that LBP is an important occupational hazard and nurses are particularly at high risk. While several studies have addressed the prevalence of LBP worldwide, the prevalence of LBP in Saudi Arabia remains unclear. In this study we aimed to estimate the prevalence and associated factors of LBP among nurses in Qassim region, Saudi Arabia.

Methods: This was a multicenter cross-sectional study carried out in four major public hospitals in Qassim region. A total of 323 nurses were recruited through a two-stage sampling method. A previously validated questionnaire was used to gather data. The main outcome measures were; LBP prevalence during working life, demographic factors, life-style factors, work-related factors and psychological factors. Multivariable logistic regression analysis was used to determine factors independently associated with LBP.

Results: The study showed that LBP prevalence was $65.6 \%(n=212)$. Over one third of study participants sought treatment for LBP $(n=82,38.7 \%)$. Age and the type of ward were found significantly associated with LBP (aOR: 0.39; 95\% Cl: 0.19, 0.77; p value $=0.007) \&(a O R: 0.36 ; 95 \% \mathrm{Cl}: 0.15,0.86 ; p$ value $=0.02)$, respectively. However, gender, working hours, number of patients, stress and smoking were not identified as LBP risk factors in this study.

Conclusion: The findings of this study suggest that LBP is a highly prevalent occupational health problem among nurses in Qassim. Young nurses 20-30 years are more likely to suffer from LBP, while nurses working in the general surgery wards have lower risk for LBP in this study. On-the-job training is essential particularly for new and young nurses on proper body mechanics when mobilizing patients or lifting heavy equipment. In addition, there is a need for evidence -based interventions to improve the work-place environment for nurses in hospitals in order to lower LBP prevalence.

\section{Background}

Low back pain (LBP) is a common complaint that needs medical attention. Indeed, LBP is the commonest musculoskeletal disorder among adults with a prevalence reaching $84 \%$ [1]. It has a complex etiology and may originate from different spinal structures including muscles and fascia, joints, ligaments, discs or nerve roots [2]. However, in many cases no definitive cause can be determined. Nonspecific LBP is a term used when the underlying cause cannot be specifically identified [1]. The diagnosis of non-specific LBP is generally made upon the exclusion of other known causes for the LBP such as infections, trauma or neoplasms [3]. It commonly refers to pain localized in the posterior region of the body extending from below the costal margin down to the gluteal folds with or without referred pain into one or both legs, lasting for at least 1 day [4]. Throughout this paper we will use the abbreviation LBP to refer to non-specific low back pain. 
LBP may result in major economic losses. Health care expenditure on LBP in terms of costs of care and treatment is significant [5]. Prior evidence has shown that recurrent back pain was strongly associated with increased odds of leaving paid employment for health related reasons [6]. LBP may also lead to many physical and psychological complications. Owing to the nature of their job nurses are considered among the groups at high risk for LBP [7-9]. Several studies identified work-related factors such as lifting and mobilizing patients, inappropriate work design, sustained postures, decreased social support, low job satisfaction, and inadequate staffing as the main risk factors for LBP among nurses [10-12]. It has also been found that LBP adversely influences the productivity of nurses and thus undermines the overall quality of healthcare services provided to beneficiaries [13]. Moreover, LBP has a great impact on the health care system, particularly in terms of work absenteeism, and escalating healthcare costs [14].

Psychosocial factors were also found to be linked with the risk for LBP [15]. The increased demand of the job in terms of prolonged working hours, night shifts, spending long time away from their families may negatively impact the psychological status of nurses. In addition, low job satisfaction, increased workload and poor work relationships may result in stress and anxiety $[16,17]$.

A little is known about the burden of LBP among nurses in Saudi Arabia. A previous study on the prevalence of LBP among physical therapists revealed a high prevalence of $89.65 \%$. The study also found that gender and duration of patient contact were associated with LBP [18].Another study which was conducted among health care workers in southwestern region of Saudi Arabia estimated LBP as 73.9\% [19]. Furthermore, a community-based survey that was carried out in Qassim has only focused on the prevalence of back pain among the general population. Over 5000 adults participated in the survey which reported a relatively low prevalence of $18.85 \%$. The survey also showed that age, depression, and certain occupations were associated with back pain [20]. A few researchers have addressed the problem of LBP in Saudi Arabia. This raises questions about how big this problem is among healthcare professionals and particularly among nurses. The sacristy of evidence for LBP in Saudi Arabia was the main driving force to carry out this investigation. In this study we aimed to determine the prevalence of low back pain among nurses working in public health sector in Qassim in order to gain insight into the magnitude of this problem and its predicting factors.

\section{Methods}

\section{Study setting}

This was a multicenter cross-sectional study carried out in Qassim region in Saudi Arabia. Qassim is located in the center of the kingdom, northwest to the capital Riyadh. It is well known for its administrative \& agricultural values. In this study ,four major public hospitals representing the four major cities in Qassim were included, namely; King Fahd Specialist Hospital (Buraidah), Ar Rass General Hospital (Ar Rass), King Saud Hospital (Onaizah), and Al Bukairiyah General Hospital, (Al Bukairiyah). 


\section{Study population}

A total of 323 nurses were recruited in this study .A two-stage sampling technique was employed. In the first stage, hospitals were selected (primary sampling units). Eligible hospitals were public facilities which provide inpatient care, and admit all types of cases. Four hospitals serving large catchment areas in Qassim were included. Secondly, a sample of professional nurses was recruited from each hospital (secondary sampling units). Those were registered nurses from both sexes who were on full-time jobs and were on duty during the data collection period. Those who were on official leave were excluded.

Eligible nurses in the selected hospitals were invited for the study. We calculated the sample size using the single population proportion equation $\left(N=Z^{2} p(1-p) / d^{2}\right)$. An assumed prevalence of LBP of $70 \%$ was used based on previous evidence [19,21,22], a precision level of $5 \%$ and $95 \%$ confidence level. That yielded the target sample size of 323 nurses.

\section{The Questionnaire}

The prevalence of low back pain and other related data were measured through the administration of an anonymous, self-administered questionnaire. The questionnaire was adopted from a previously published study by Branny and Newell, and we used it unchanged [23]. It is composed of four parts; jobrelated history, LBP characteristics, LBP treatment options, and socio-demographic factors. LBP was defined with an aid of a diagram to depict the area of pain localization. The definition and illustration used in this questionnaire were the same used in other British surveys on back pain [21]. Questionnaires were hand distributed, and informed consent was obtained from nurses who agreed to take part in the study. The study protocol was reviewed and approved by the regional institutional review board in Qassim.

\section{Data Analysis}

The statistical analysis was performed in two steps. First, descriptive statistics analysis was performed. Background data related to socio-demographic risk factors, work history and prevalence of LBP were presented as simple frequencies (and percentages). Secondly, inferential statistics in the form of logistic regression analyses were performed. Initially univariate logistic regression was used to calculate crude odds ratios (Unadjusted ORs) and determine potential risk factors for LBP separately. Next, multivariate logistic regression analysis was performed to obtain adjusted Odds ratios (aORs) and 95\% confidence intervals $(95 \% \mathrm{Cl})$ to identify variables significantly associated with LBP considering the effect of potential confounders.

\section{Results}

In this study, a total of 323 questionnaires were distributed.All participants completed the questionnaire resulting in a response rate of $100 \%$. For ease of administration all questionnaire items were all closed- 
ended. In table (1) the socio-demographic profile of participants was described. Female comprised the vast majority among participants $(n=302,93.5 \%)$. Most participants $(n=195,60.4 \%)$ belong to the age group 20-30 years. Smoking habit was observed among only $5 \%(n=16)$ of the participants. Regular physical activity was reported by $31 \%(n=100)$ of participants. Feeling low in mood or under stressed were reported by $77.1 \%$ and $82.9 \%$ of participants, respectively.

Table (2) shows the work history of the participants. The majority of participants in this study were staff nurses $(n=265,82.0 \%)$. Charge nurses and healthcare assistants comprised $17.1 \%$ and $0.9 \%$ respectively. A total of $183(56 \%)$ of the study participants spent $1-5$ years work duration in their current post. More than two thirds of the enrolled nurses $(n=254,78.6 \%)$ reported working on day and night shifts alike. The majority of nurses ( $n=262,81.1 \%$ ) work over 40 hours per week. Moreover, $140(43.3 \%)$ of participants had to work additional hours exceeding 10 hours on average per month. On a regular shift, more than half of participants $(n=187,57.9 \%)$ reported an average of $1-5$ patients require assistance mobilizing , while $34.4 \%$ reported a higher number exceeding 5 patients per shift. Nurses in this study worked in a wide variety of wards, however, at the time of the survey a considerable number of them worked in three main wards; general medical, intensive care,and general surgical ward comprising $19.8 \% 21.7 \%$ and $18.9 \%$ respectively.

The prevalence of LBP and its related characteristics are shown in table (3). This study showed a $65.6 \%$ prevalence of LBP among nurses in Qassim. over one third of them sought treatment for LBP $(n=82$, $38.7 \%$ ). Similarly, at least one third reported difficulty performing daily activities such as getting out of bed $(47.25 \%)$, sleep through the night $(48.1 \%)$, and put on socks $(37.7 \%)$. However, only few reported sickness absence due to $\operatorname{LBP}(n=65,31.7 \%)$.

Table (4) describes the univeraite and multivariate logistic regression analysis of factors significantly associated with LBP. The univeriate anlaysis showed that working on a general surgical ward (OR: 0.39; $95 \% \mathrm{Cl}: 0.21,0.73 ; p$ value $=0.004)$, and age over 40 years (OR: $0.35 ; 95 \% \mathrm{Cl}: 0.16,0.78 ; p$ value $=0.01)$ were significant factors. In the multivariate logistic regression analysis, the same variables were also found independently associated with LBP expressed as; working on a general surgical ward (aOR: 0.39; $95 \% \mathrm{Cl}: 0.19,0.77 ; p$ value $=0.007$ ), and age over 40 years (aOR: $0.36 ; 95 \% \mathrm{Cl}: 0.15,0.86 ; p$ value $=0.02$ ) However, smoking, physical activity, gender, work duration, length of working hours per week, number of patients require assistance mobilizing on a shift, depression and stress were not independent risk factors for LBP ( $p$ value $\geq 0.05)$.

\section{Discussion}

This study aimed to objectively measure the prevalence of LBP and its risk factors among nurses in Qassim. This research is potentially the first comprehensive analysis of LBP involving four major public health facilities in Qassim. We aimed to measure the prevalence of LBP of nurses during their working life. The study found the prevalence of LBP was $65.5 \%$. The literature shows a wide variation in LBP prevalence. However, the numbers are invariably high as reported in previous intentional studies 
conducted among nurses in Switzerland [24], Nigeria [25], Slovenia [26], Jordan [27], and South Africa [28] .Nationally, LBP prevalence was reported as $74.2 \%$, and $48.4 \%$ among operating room staff in Makkah \& Taif respectively $[29,30]$. In addition, a study showed a prevalence of $53.2 \%$ among nurses in Sudayr region [31]. Those findings reflect the burden of LBP among an important healthcare workforce. However, no significant gender-related differences in prevalence were reported. This finding is inconsistent with previous studies that showed a higher prevalence of LBP among females compared to males [25, 32]. Nurses are at the heart of healthcare systems worldwide and have indispensible role in the delivery of healthcare. Our results also showed that $61.8 \%$ of nurses who reported LBP had suffered from pain spreading to below their knees and over $38 \%$ of them had sought treatment for LBP. In addition, over $31 \%$ of nurses in the study reported absence from work due to LBP. This finding is in agreement with a previous Saudi study indicating that almost $44 \%$ of nurses reported considering changing their job due to LBP [33].

In depth analysis of the potential risk factors for LBP, shows that occupation-related back pain is a complex phenomenon and its underlying causes are multifactorial. In the literature A web of causation of LBP was described which includes; demographical factors, lifestyle factors, occupational factors, and psychological factors [34].

Regarding the demographic characteristics and based on the logistic regression analyses, our study found that age had significant different odds for the study participants with LBP when compared with those without LBP. Nurses aged over 40 years were less likely to develop LBP when compared to nurses of younger age. Specifically, they had $64 \%$ less likely odds of developing LBP. Our result is in contrast with other studies which show LBP is associated with older age $[25,35,36]$. On other hand, however, this result is supported by past evidence which indicate that younger nurses between 20-30 years had the highest prevalence of LBP [37]. This might be due to the fact that younger nurses are more likely to be involved in heavy workload as healthcare assistants or staff nurses. This type of workload involves assistance mobilizing of patients or instruments and hence requires more musculoskeletal effort. While older, probably senior nurses are expected to be responsible for organizational or supervisory jobs with less musculoskeletal strains. This finding could also be attributed to training. Older nursing staff would have received extensive training on health and occupational safety and had developed awareness and skills on safe posture technique over time and so less likely to adopt faulty postures. Additionally, younger nurses with limited work experience and high job demand may suffer more from psychological stress compared to older nurses who might have already developed effective strategies to cope with work and personal stress. This explanation is supported by a previous study which indicates that younger nurses have higher job-related stress [37]. Another plausible explanation for the decreased odds for LBP among older nurses is the healthy worker effect. LBP sufferers tend to change their employment or quit their jobs, whereas healthy nurses are more likely to stay in their jobs [38].

This study also investigated the effect of life style factors on LBP. Evidence from the literature suggests a strong association between smoking and LBP confirming that smokers are more prone to LBP [39]. It has been found that nicotine significantly decreases the amount of oxygen reaching the muscles resulting in 
increased likelihood for muscular injury and degenerative changes [40]. Additionally, it is plausible that smoking induces coughing reflexes which may further increase the risk among smokers for LBP. However, no significant effect of smoking could be detected in this study. A previous study showed similar results [41]. Historically, females in the Arab world are less likely to report their smoking habits for cultural reasons. Over $90 \%$ of the study participants were females and therefore under-reporting could be the reason why smoking couldn`t be detected as a significant predicator for LBP in this study. Similarly, no significant association was found between physical activity and LBP in this study. Interestingly, past evidence detected that physical exercise such as pilates intervention reduces LBP [42]. Some authors, however, described the relationship between physical activity and LBP as U-shaped, where moderate increased risk was exclusively found for those engaged in strenuous activities and those living a sedentary lifestyle [43].

Beside their professional duties nurses are expected to assist in other ancillary services such as mobilizing patients or equipment. Five occupation-related risk factors were tested in this study, those were; working hours per week, work duration, additional work hours per week, type of ward and number of patients requiring mobilization. Of those, only the factor "type of ward" remained statistically significant after adjusting for potential cofounders. Prior evidence has shown that LBP prevalence among nurses working in intensive care units was particularly high [44]. Another study showed that nurses working in the Obstetrics and Gynecology had a high prevalence of LBP exceeding 26\% [25]. A different study revealed that the prevalence of LBP was higher among nurses working in surgical wards.[45]. Surprisingly, our study found that nurses working in the general surgery ward have $61 \%$ less odds for LBP compared to other departments. Surgical nurses are expected to be more exposed to back pain and injuries due to the nature of the work compared to nursing duties in other wards. Examples of risk include working with dependent patients, standing in one position during lengthy surgical operations, holding patient extremities, moving anesthetized patients, lifting equipment, carrying heavy trays, etc. However, nurses working in surgical departments might have already developed better awareness of this particular risk and hence have become well prepared for their jobs. They might have better skills related to body mechanics and ergonomics compared to nurses working in other wards resulting in lower risk among them. Alternatively, the significant association between working in a surgical ward and lower risk for LBP

might indirectly be related to the perceived amount of workload in terms of less number of patients, and a shorter hospital stay of patients in surgical wards. In fact, it is not clear from our data the length of work experience in wards for nurses at the time of the study and its relation to the onset of LBP. Nurses typically rotate between wards during their working life and it is difficult to determine the temporal association between the type of ward and development of LBP in this study. Psychological factors were documented by other studies to have significant association with LBP [16, 33, 34], however stress and low mood were not identified as risk factors of LBP in this study.

\section{Limitations}

Our findings have provided an important scientific contribution. It clearly demonstrate that LBP is a highly prevalent health problem among nurses in Qassim.. However, our work has two limitations. First, although 
we were able to study several variables, temporal association could not be established between LBP and significant variables due to the cross-sectional design. Second, response bias could not be excluded since data were collected through self-reporting. The effect of this bias was minimized through the use of closed - ended, and concise answer choices in the study questionnaire. Also, the questions were direct and clearly phrased. In general, despite limitations we believe that our work adds substantially to a growing body of literature on the prevalence of LBP among nurses in Saudi Arabia.

\section{Conclusions}

The evidence from this study suggests that LBP is a common occupational health problem among nurses. The high LBP prevalence reported in this study is comparable to other countries. However, targeted interventions are needed to reduce this prevalence. It has been observed that younger nurses who constitute the largest group of the ward team in any hospital are more prone to have LBP. Nurses work in direct contact with patients, and their health not only influences their job satisfaction but also patient safety and quality of healthcare. Interestingly, the results of this study showed that nurses working in general surgery wards where one would expect a heavy workload have lower risk for LBP. In our view, these results have important managerial implications. Improving the workplace environment for nurses is essential to reduce the risk for LBP. Ergonomics research is required to identify evidence-based interventions that would help promote the health and safety of nurses, as well as on-the-job training to raise nurses' awareness and improve their skills on how to use body mechanics and avoid risky postures.

\section{Abbreviations}

95\% Cl: 95\% Confidence Interval.

aOR: Adjusted Odds Ratio.

LBP: Low Back Pain

uOR: Unadjusted Odds ratio.

$N=Z^{2} p(1-p) / d^{2}$

\section{Where:}

$\mathrm{N}$ : Target sample size

Z: The standard normal variant at $5 \%$ type 1 error ( $p$ value $<0.05)$, which is 1.96 .

P: Expected prevalence of low back pain among nurses obtained from previously published studies.

D: Absolute error or precision, decided as $5 \%$. 


\section{Declarations}

\section{Ethics approval and consent to participate}

The study has been approved by the Regional Research Ethics Committee under the General Directorate of Health affairs / Ministry of Health in Qassim Province. It has been registered at the National Committee of Bio.\& medical ethics in Saudi Arabia (Reference Number: H-04-Q-001). Participation was voluntary, and a written consent was obtained from participants prior to completing the questionnaire.

\section{Consent to publish}

Not applicable.

\section{Availability of data and materials}

The datasets generated and analyzed during the current study are not publicly available due to privacy restrictions. Respondents were informed during the consent process that the data they provide would be available only to the research team. Data are however available from the authors upon reasonable request and with permission from the Saudi Ministry of Health.

\section{Competing interests}

The authors declare that they have no competing interests.

\section{Funding}

No funding was obtained for this study.

\section{Authors' Contributions}

AE was the principal investigator \& corresponding author. She participated in the design and protocol review, guided the data analysis, and interpretation, and provided critical revision of the initial drafts of the manuscript. She provided coordination and made a substantial contribution toward finalizing the manuscript. HA, RIA, MA, NA, RKA and SA collaboratively contributed to the conception of the study idea, design, literature review, protocol preparation, data collection, data analysis \& interpretation, and wrote initial drafts of the manuscript. All authors have read and approved the manuscript.

\section{Acknowledgements}


Researchers would like to thank the Deanship of Scientific Research, Qassim University for funding publication of this project. We would also like to extend our thanks and appreciation to the administrators and nurses from the four hospitals included in this study. Particular thanks to Dr. Alaa Ali AIDahlawi for his support and assistance with data collection. Also, special thanks to Afrah H. AlAzmi, and Mohammed F. AlHarbi for their efforts. Our sincere appreciation extends to all those who have contributed to this work.

\section{References}

1. Balagué F, Mannion AF, Pellisé F, Cedraschi C. Non-specific low back pain. Lancet. 2012;379(9814):482-91.

2. Allegri M, Montella S, Salici F, Valente A, Marchesini M, Compagnone C, et al. Mechanisms of low back pain: a guide for diagnosis and therapy. F1000Res. 2016;5:1530.

3. Koes BW, van Tulder MW, Thomas S. Diagnosis and treatment of low back pain. BMJ. 2006;332(7555):1430-4.

4. Hoy D, March L, Brooks P, Blyth F, Woolf A, Bain C, et al. The global burden of low back pain: estimates from the Global Burden of Disease 2010 study. Ann Rheum Dis. 2014;73(6):968-74.

5. Kim LH, Vail D, Azad TD, Bentley JP, Zhang Y, Ho AL, et al. Expenditures and health care utilization among adults with newly diagnosed low back and lower extremity pain. JAMA Netw Open. 2019;2(5):e193676.

6. Lallukka T, Mänty M, Cooper C, Fleischmann M, Kouvonen A, Walker-Bone KE, et al. Recurrent back pain during working life and exit from paid employment: a 28-year follow-up of the Whitehall II Study. Occup Environ Med. 2018;75(11):786-91.

7. Genevay S, Cedraschi C, Courvoisier DS, Perneger TV, Grandjean R, Griesser A-C, et al. Work related characteristics of back and neck pain among employees of a Swiss University Hospital. Joint Bone Spine. 2011;78(4):392-7.

8. Yassi A, Lockhart K. Work-relatedness of low back pain in nursing personnel: a systematic review. Int J Occup Environ Health. 2013;19(3):223-44.

9. Eriksen W, Bruusgaard D, Knardahl S. Work factors as predictors of intense or disabling low back pain; a prospective study of nurses' aides. Occup Environ Med. 2004;61(5):398-404.

10. Ibrahim MI, Zubair IU, Yaacob NM, Ahmad MI, Shafei MN. Low back pain and its associated factors among nurses in public hospitals of Penang, Malaysia. Int J Environ Res Public Health. 2019;16(21):4254.

11. Zhang Q, Dong H, Zhu C, Liu G. Low back pain in emergency ambulance workers in tertiary hospitals in China and its risk factors among ambulance nurses: a cross-sectional study. BMJ Open. 2019;9(9):e029264.

12. Munabi IG, Buwembo W, Kitara DL, Ochieng J, Mwaka ES. Musculoskeletal disorder risk factors among nursing professionals in low resource settings: a cross-sectional study in Uganda. BMC Nurs. 
2014;13(1):7.

13. de Castro AB. Handle with care: The American Nurses Association's Campaign to address workrelated musculoskeletal disorders. Online J Issues Nurs. 2004;9(3):3.

14. Dagenais S, Caro J, Haldeman S. A systematic review of low back pain cost of illness studies in the United States and internationally. Spine J. 2008;8(1):8-20.

15. Bernal D, Campos-Serna J, Tobias A, Vargas-Prada S, Benavides FG, Serra C. Work-related psychosocial risk factors and musculoskeletal disorders in hospital nurses and nursing aides: a systematic review and meta-analysis. Int J Nurs Stud. 2015;52(2):635-48.

16. Yip Y. A study of work stress, patient handling activities and the risk of low back pain among nurses in Hong Kong. J Adv Nurs. 2001;36(6):794-804.

17. Yip VYB. New low back pain in nurses: work activities, work stress and sedentary lifestyle. J Adv Nurs. 2004;46(4):430-40.

18. Alghadir A, Zafar H, Iqbal ZA, Al-Eisa E. Work-related low back pain among physical therapists in Riyadh, Saudi Arabia. Workplace Health Saf. 2017;65(8):337-45.

19. Alnaami I, Awadalla NJ, Alkhairy M, Alburidy S, Alqarni A, Algarni A, et al. Prevalence and factors associated with low back pain among health care workers in southwestern Saudi Arabia. BMC Musculoskelet Disord. 2019;20(1):56.

20. Al-Arfaj AS, Al-Saleh SS, Alballa SR, Al-Dalaan AN, Bahabri SA, Al-Sekeit MA, et al. How common is back pain in Al-Qaseem region. Saudi Med J. 2003;24(2):170-3.

21. Waddell G. The epidemiology of back pain. The back pain revolution. 2nd ed. Edinburgh: Churchill Livingstone; 2004. pp. 71-89.

22. Asadi P, Monsef Kasmaei V, Zia Ziabari SM, Zohrevandi B. The prevalence of low back pain among nurses working in Poursina hospital in Rasht, Iran. J Emerg Pr Trauma. 2015;2(1):11-5.

23. Branney J, Newell D. Back pain and associated healthcare seeking behaviour in nurses: A survey. Clin chiropr. 2009;12(4):130-43.

24. Maul I, Läubli T, Klipstein A, Krueger H. Course of low back pain among nurses: a longitudinal study across eight years. Occup Environ Med. 2003;60(7):497-503.

25. Sikiru L, Hanifa S. Prevalence and risk factors of low back pain among nurses in a typical Nigerian hospital. Afr Health Sci. 2010;10(1):26-30.

26. Skela-Savič B, Pesjak K, Hvalič-Touzery S. Low back pain among nurses in Slovenian hospitals: cross-sectional study. Int Nurs Rev. 2017;64(4):544-51.

27. Suliman M. Prevalence of low back pain and associated factors among nurses in Jordan. Nurs Forum. 2018;53(4):425-31.

28. Dlungwane T, Voce A, Knight S. Prevalence and factors associated with low back pain among nurses at a regional hospital in KwaZulu-Natal, South Africa. Health SA Gesondheid. 2018;23:1082.

29. Bin Homaid M, Abdelmoety D, Alshareef W, Alghamdi A, Alhozali F, Alfahmi N, et al. Prevalence and risk factors of low back pain among operation room staff at a Tertiary Care Center, Makkah, Saudi 
Arabia: a cross-sectional study. Ann Occup Environ Med. 2016;28(1):1.

30. Keriri HM. Prevalence and risk factors of low back pain among nurses in operating rooms, taif, Saudi Arabia. J Med Sci Res. 2013;4(1):3.

31. Al Dajah S, Al DA. Prevalence and risk factors of low back pain among nurses in sudayr region. ESJ. 2013;9(33):198-205.

32. Azizpour Y, Delpisheh A, Montazeri Z, Sayehmiri K. Prevalence of low back pain in Iranian nurses: a systematic review and meta-analysis. BMC Nurs. 2017;16(1):50.

33. Jradi $\mathrm{H}$, Alanazi $\mathrm{H}$, Mohammad Y. Psychosocial and occupational factors associated with low back pain among nurses in Saudi Arabia. J Occup Health. 2020;62(1):e12126.

34. Budhrani-Shani P, Berry DL, Arcari P, Langevin H, Wayne PM. Mind-body exercises for nurses with chronic low back pain: An evidence-based review. Nurs Res Pract. 2016;2016:9018036.

35. Sadeghian F, Hosseinzadeh S, Aliyari R. Do psychological factors increase the risk for low back pain among nurses? A comparing according to cross-sectional and prospective analysis. Saf Health Work. 2014;5(1):13-6.

36. Shieh S-H, Sung F-C, Su C-H, Tsai Y, Hsieh VC-R. Increased low back pain risk in nurses with high workload for patient care: A questionnaire survey. Taiwan J Obstet Gynecol. 2016;55(4):525-9.

37. Purcell SR, Kutash M, Cobb S. The relationship between nurses' stress and nurse staffing factors in a hospital setting: Nurse stress. J Nurs Manag. 2011;19(6):714-20.

38. Harkness EF, Macfarlane GJ, Nahit ES, Silman AJ, McBeth J. Risk factors for new-onset low back pain amongst cohorts of newly employed workers. Rheumatology. 2003;42(8):959-68.

39. Green BN, Johnson CD, Snodgrass J, Smith M, Dunn AS. Association between smoking and back pain in a cross-section of adult Americans. Cureus. 2016;8(9):e806.

40. Akmal M, Kesani A, Anand B, Singh A, Wiseman M, Goodship A. Effect of nicotine on spinal disc cells: a cellular mechanism for disc degeneration. Spine (Phila Pa 1976). 2004;29(5):568-75.

41. 10.26717/bjstr.2017.01.000613

Gim CS. Factors associated with low back pain among nurses in critical care units, hospital Universiti sains Malaysia. Biomed J Sci Tech Res [Internet]. 2017;1(7). Available from: http://dx.doi.org/10.26717/bjstr.2017.01.000613.

42. Stieglitz DD, Vinson DR, Hampton MDC. Equipment-based Pilates reduces work-related chronic low back pain and disability: A pilot study. J Bodyw Mov Ther. 2016;20(1):74-82.

43. Heneweer H, Vanhees L, Picavet HSJ. Physical activity and low back pain: a U-shaped relation? Pain. 2009;143(1-2):21-5.

44. Ovayolu O, Ovayolu N, Genc M, Col-Araz N. Frequency and severity of low back pain in nurses working in intensive care units and influential factors. Pak J Med Sci Q. 2014;30(1):70-6.

45. Thon CC, Feng PKJ, Lian CW. Risk factors of low back pain among nurses working in Sarawak General Hospital. Health Environ J. 2016;7(1):13-24. 


\section{Tables}

Table (1): Demographic \& life style characteristics of nurses, Qassim, Saudi Arabia $(n=323)$

\begin{tabular}{|c|c|}
\hline Characteristic & $N(\%)$ \\
\hline \multicolumn{2}{|l|}{ Gender } \\
\hline Male & $21(6.5 \%)$ \\
\hline Female & $302(93.5 \%)$ \\
\hline \multicolumn{2}{|l|}{ Age group } \\
\hline $20-30$ years & $195(60.4 \%)$ \\
\hline $31-40$ years & $99(30.7 \%)$ \\
\hline Over 40 years & $29(9.0 \%)$ \\
\hline \multicolumn{2}{|l|}{ Smoking } \\
\hline No & 307 (95\%) \\
\hline Yes & $16(5.0 \%)$ \\
\hline \multicolumn{2}{|c|}{ Regular Physical activity } \\
\hline No & $223(69.0 \%)$ \\
\hline Yes & $100(31.0 \%)$ \\
\hline \multicolumn{2}{|c|}{ Feeling low in mood } \\
\hline Never & $74(22.9 \%)$ \\
\hline Occasionally & $215(66.6 \%)$ \\
\hline Frequently & $34(10.5 \%)$ \\
\hline \multicolumn{2}{|c|}{ Feeling under stress } \\
\hline Never & $55(17.0 \%)$ \\
\hline Occasionally & $202(62.5 \%)$ \\
\hline Frequently & $66(20.4 \%)$ \\
\hline
\end{tabular}

Table (2): Work-related characteristics of nurses, Qassim, Saudi Arabia ( $\mathrm{n}=323$ 


\begin{tabular}{|c|c|}
\hline Characteristic & $N(\%)$ \\
\hline \multicolumn{2}{|l|}{ Current post } \\
\hline Healthcare assistant & $3(0.9 \%)$ \\
\hline Staff nurse & $265(82.0 \%)$ \\
\hline Charge nurse /sister & $55(17.1 \%)$ \\
\hline \multicolumn{2}{|c|}{ Work duration in the current post } \\
\hline less than one year & $41(12.7 \%)$ \\
\hline $1-5$ years & $183(56.7 \%)$ \\
\hline More than 5 years & $99(30.7 \%)$ \\
\hline \multicolumn{2}{|l|}{ Type of shifts } \\
\hline Days only & $67(20.7 \%)$ \\
\hline Nights only & $2(0.6 \%)$ \\
\hline Days and nights & $254(78.6 \%)$ \\
\hline \multicolumn{2}{|l|}{ Work hours per week } \\
\hline $20-40$ & $61(18.9 \%)$ \\
\hline Over 40 years & $262(81.1 \%)$ \\
\hline \multicolumn{2}{|c|}{ Additional work hours per month } \\
\hline None & $41(12.7 \%)$ \\
\hline $1-10$ & $142(44.0 \%)$ \\
\hline More than 10 & $140(43.3 \%)$ \\
\hline \multicolumn{2}{|c|}{ Average number of patients require assistance mobilizing per shift } \\
\hline None & $25(7.7 \%)$ \\
\hline $1-5$ & $187(57.9 \%)$ \\
\hline Over 5 patients & $111(34.4 \%)$ \\
\hline \multicolumn{2}{|l|}{ Type of ward } \\
\hline General medical & $64(19.8 \%)$ \\
\hline ICU & $70(21.7 \%)$ \\
\hline General surgical & $61(18.9 \%)$ \\
\hline Others & 128 (39.6\%) \\
\hline
\end{tabular}


Table (3): Prevalence of low back pain among nurses, Qassim, Saudi Arabia $(n=323)$.

\begin{tabular}{|ll|}
\hline Characteristic & $\mathrm{N}(\%)$ \\
\hline Low back pain & $212(65.6 \%)$ \\
\hline Treatment sought for low back pain & $82(38.7 \%)$ \\
\hline Low back pain Spread down the leg to below the knee & $131(61.8 \%)$ \\
\hline Low back pain causing difficulty in daily activities below \\
\hline Getting out of bed & $100(47.2 \%)$ \\
\hline Sleep through the night & $102(48.1 \%)$ \\
\hline Standing up for 20-30minutes. & $121(57.1 \%)$ \\
\hline Walking $300-400$ meter & $107(50.5 \%)$ \\
\hline Climb one flight of stairs & $107(50.5 \%)$ \\
\hline Put on socks & $80(37.7 \%)$ \\
\hline Sickness Absence due to low back pain & $147(68.3 \%)$ \\
\hline None & $42(19.8 \%)$ \\
\hline $1-6$ days & $15(7.0 \%)$ \\
\hline $1-4$ weeks & $8(3.8 \%)$ \\
\hline more than 4 weeks & \\
\hline
\end{tabular}

Table (4): Univariate \& Multivariate logistic regression analysis of factors associated with low back pain among nurses,Qassim,Saudi Arabia $(n=323)$ 


\begin{tabular}{|c|c|c|c|c|c|c|}
\hline \multirow[t]{2}{*}{ Characteristic } & \multicolumn{2}{|c|}{ Low Back Pain } & \multirow[t]{2}{*}{ UOR (95\% Cl) } & \multirow[t]{2}{*}{ p.value } & \multirow[t]{2}{*}{$\mathrm{AOU}(95 \% \mathrm{Cl})$} & \multirow[t]{2}{*}{ p.value } \\
\hline & Yes(\%) & $\begin{array}{l}\text { No } \\
(\%)\end{array}$ & & & & \\
\hline \multicolumn{7}{|c|}{ Working hours per week } \\
\hline \multirow[t]{2}{*}{$20-40$} & 46 & 15 & \multirow[t]{2}{*}{1} & & \multirow[t]{2}{*}{1} & \\
\hline & $75.4 \%$ & $24.6 \%$ & & & & \\
\hline \multirow[t]{2}{*}{ More than 40} & 166 & 96 & \multirow{2}{*}{$\begin{array}{l}0.564(0.299- \\
1.064)\end{array}$} & \multirow[t]{2}{*}{0.077} & \multirow{2}{*}{$\begin{array}{l}0.628(0.314- \\
1.256)\end{array}$} & \multirow[t]{2}{*}{0.189} \\
\hline & $63.4 \%$ & $36.6 \%$ & & & & \\
\hline \multicolumn{7}{|c|}{ Work duration in current post } \\
\hline \multirow{2}{*}{$\begin{array}{l}\text { Less than one } \\
\text { year }\end{array}$} & 26 & 15 & \multirow[t]{2}{*}{ Reference } & & \multirow[t]{2}{*}{ Reference } & \\
\hline & $63.4 \%$ & $36.6 \%$ & & & & \\
\hline \multirow[t]{2}{*}{$1-5$ years } & 119 & 64 & \multirow{2}{*}{$\begin{array}{l}1.073(0.530- \\
2.170)\end{array}$} & \multirow[t]{2}{*}{0.845} & \multirow{2}{*}{$\begin{array}{l}0.995(0.467- \\
2.120)\end{array}$} & \multirow[t]{2}{*}{0.990} \\
\hline & $65.0 \%$ & $35.0 \%$ & & & & \\
\hline \multirow{2}{*}{$\begin{array}{l}\text { More than } \\
5 \text { years }\end{array}$} & 67 & 32 & \multirow{2}{*}{$\begin{array}{l}1.208(0.564- \\
2.589)\end{array}$} & \multirow[t]{2}{*}{0.627} & \multirow{2}{*}{$\begin{array}{l}1.425(0.608- \\
3.337)\end{array}$} & \multirow[t]{2}{*}{0.415} \\
\hline & $65.6 \%$ & $34.4 \%$ & & & & \\
\hline \multicolumn{7}{|c|}{ Additional work hours per week } \\
\hline \multirow[t]{2}{*}{ None } & 31 & 10 & \multirow[t]{2}{*}{ Reference } & & Reference & \\
\hline & $75.6 \%$ & $24.4 \%$ & & & & \\
\hline $1-10$ & 92 & 50 & $0.594(0.269-$ & 0.197 & $0.581(0.241-$ & 0.228 \\
\hline & $64.8 \%$ & $35.2 \%$ & & & & \\
\hline More than 10 & 89 & 51 & $0.563(0.255-$ & 0.155 & $0.531(0.217-$ & 0.166 \\
\hline & $63.6 \%$ & $36.4 \%$ & & & & \\
\hline Type of ward & & & & & & \\
\hline General medical & 40 & 24 & $0.627(0.331-$ & 0.152 & 0.669 (0.335- & 0.254 \\
\hline & $62.5 \%$ & $37.5 \%$ & & & & \\
\hline ICU & 48 & 22 & $0.821(0.434-$ & 0.544 & $0.835(0.426-$ & 0.599 \\
\hline & $68.6 \%$ & $31.4 \%$ & & & & \\
\hline General surgical & 31 & 30 & 0.389 (0.206- & $0.004^{*}$ & $0.387(0.194$ & 0.007 \\
\hline & $50.8 \%$ & $49.2 \%$ & & & & \\
\hline
\end{tabular}




\begin{tabular}{|c|c|c|c|c|c|c|}
\hline \multirow[t]{2}{*}{ Characteristic } & \multicolumn{2}{|c|}{ Low Back Pain } & \multirow[t]{2}{*}{ UOR (95\% Cl) } & \multirow[t]{2}{*}{ p.value } & \multirow[t]{2}{*}{ AOU (95\% Cl) } & \multirow[t]{2}{*}{ p.value } \\
\hline & Yes(\%) & $\begin{array}{l}\text { No } \\
\text { (\%) }\end{array}$ & & & & \\
\hline \multirow[t]{2}{*}{ others } & 93 & 35 & \multirow[t]{2}{*}{ Reference } & & \multirow[t]{2}{*}{ Reference } & \\
\hline & $72.7 \%$ & $27.3 \%$ & & & & \\
\hline \multicolumn{7}{|c|}{ Patients require mobilizing } \\
\hline \multirow[t]{2}{*}{ None } & 16 & 9 & \multirow[t]{2}{*}{ Reference } & & \multirow[t]{2}{*}{ Reference } & \\
\hline & $64.0 \%$ & $36.0 \%$ & & & & \\
\hline \multirow[t]{2}{*}{$1-5$} & 119 & 68 & \multirow{2}{*}{$\begin{array}{l}0.984(0.413- \\
2.348)\end{array}$} & \multirow[t]{2}{*}{0.972} & \multirow{2}{*}{$\begin{array}{l}1.207(0.437- \\
3.331)\end{array}$} & \multirow[t]{2}{*}{0.716} \\
\hline & $63.6 \%$ & $36.4 \%$ & & & & \\
\hline \multirow[t]{2}{*}{ More than 5} & 77 & 34 & \multirow{2}{*}{$\begin{array}{l}1.274(0.512- \\
3.168)\end{array}$} & \multirow[t]{2}{*}{0.602} & \multirow{2}{*}{$\begin{array}{l}1.513(0.521- \\
4.392)\end{array}$} & \multirow[t]{2}{*}{0.446} \\
\hline & $69.4 \%$ & $30.6 \%$ & & & & \\
\hline \multicolumn{7}{|l|}{ Gender } \\
\hline \multirow[t]{2}{*}{ Male } & 14 & 7 & \multirow[t]{2}{*}{1} & & \multirow[t]{2}{*}{1} & \\
\hline & $66.7 \%$ & $33.3 \%$ & & & & \\
\hline \multirow[t]{2}{*}{ Female } & 198 & 104 & \multirow{2}{*}{$\begin{array}{l}0.952(0.373- \\
2.432)\end{array}$} & \multirow[t]{2}{*}{0.918} & \multirow{2}{*}{$\begin{array}{l}0.660(0.214- \\
2.038)\end{array}$} & \multirow[t]{2}{*}{0.470} \\
\hline & $65.6 \%$ & $34.4 \%$ & & & & \\
\hline Age group & & & & & & \\
\hline $20-30$ years & 136 & 59 & Reference & & Reference & \\
\hline & $69.7 \%$ & $30.3 \%$ & & & & \\
\hline $31-40$ years & 63 & 36 & $0.759(0.455-$ & 0.291 & $0.645(0.356-$ & 0.148 \\
\hline & $63.6 \%$ & $36.4 \%$ & & & & \\
\hline Over 40 years & 13 & 16 & $0.352(0.159-$ & $0.010^{\star}$ & $0.356(0.148$ & 0.022 \\
\hline & $44.8 \%$ & $55.2 \%$ & & & & \\
\hline Smoking & & & & & & \\
\hline No & 203 & 104 & 1 & & 1 & \\
\hline & $66.1 \%$ & $33.9 \%$ & & & & \\
\hline Yes & 9 & 7 & $0.659(0.239-$ & 0.421 & 0.638 (0.195- & 0.456 \\
\hline & $56.3 \%$ & $43.8 \%$ & & & & \\
\hline
\end{tabular}




\begin{tabular}{|c|c|c|c|c|c|c|}
\hline \multirow[t]{2}{*}{ Characteristic } & \multicolumn{2}{|c|}{ Low Back Pain } & \multirow[t]{2}{*}{ UOR (95\% Cl) } & \multirow[t]{2}{*}{ p.value } & \multirow[t]{2}{*}{ AOU $(95 \% \mathrm{Cl})$} & \multirow[t]{2}{*}{ p.value } \\
\hline & Yes(\%) & $\begin{array}{l}\text { No } \\
\text { (\%) }\end{array}$ & & & & \\
\hline \multicolumn{7}{|c|}{ Regular Physical activity } \\
\hline \multirow[t]{2}{*}{ No } & 146 & 77 & \multirow[t]{2}{*}{1} & & \multirow[t]{2}{*}{1} & \\
\hline & $65.5 \%$ & $34.5 \%$ & & & & \\
\hline \multirow[t]{2}{*}{ Yes } & 66 & 34 & \multirow{2}{*}{$\begin{array}{l}1.024(0.623- \\
1.683)\end{array}$} & \multirow[t]{2}{*}{0.926} & \multirow{2}{*}{$\begin{array}{l}1.078(0.621- \\
1.874)\end{array}$} & \multirow[t]{2}{*}{0.789} \\
\hline & $66.0 \%$ & $34.0 \%$ & & & & \\
\hline \multicolumn{7}{|c|}{ Feeling low in mood } \\
\hline \multirow[t]{2}{*}{ Never } & 47 & 27 & \multirow[t]{2}{*}{ Reference } & & \multirow[t]{2}{*}{ Reference } & \\
\hline & $63.5 \%$ & $36.5 \%$ & & & & \\
\hline \multirow[t]{2}{*}{ Occasionally } & 140 & 75 & \multirow{2}{*}{$\begin{array}{l}1.072(0.619- \\
1.859)\end{array}$} & \multirow[t]{2}{*}{0.803} & \multirow{2}{*}{$\begin{array}{l}1.050(0.489- \\
2.252)\end{array}$} & \multirow[t]{2}{*}{0.901} \\
\hline & $65.1 \%$ & $34.9 \%$ & & & & \\
\hline \multirow[t]{2}{*}{ Frequently } & 25 & 9 & \multirow{2}{*}{$\begin{array}{l}1.596(0.651- \\
3.913)\end{array}$} & \multirow[t]{2}{*}{0.307} & \multirow{2}{*}{$\begin{array}{l}1.388(0.433- \\
4.453)\end{array}$} & \multirow[t]{2}{*}{0.581} \\
\hline & $73.5 \%$ & $26.5 \%$ & & & & \\
\hline \multicolumn{7}{|c|}{ Feeling under stress } \\
\hline \multirow[t]{2}{*}{ Never } & 33 & 22 & \multirow[t]{2}{*}{ Reference } & & \multirow[t]{2}{*}{ Reference } & \\
\hline & $60.0 \%$ & $40.0 \%$ & & & & \\
\hline \multirow[t]{2}{*}{ Occasionally } & 132 & 70 & \multirow{2}{*}{$\begin{array}{l}1.257(0.681- \\
2.319)\end{array}$} & 0.464 & $1.491(0.631-$ & 0.362 \\
\hline & $65.3 \%$ & $34.7 \%$ & & & & \\
\hline Frequently & 47 & 19 & $1.649(0.773-$ & 0.196 & $1.742(0.609-$ & 0.301 \\
\hline & $71.2 \%$ & $28.8 \%$ & & & & \\
\hline * Significant & & & & & & \\
\hline
\end{tabular}

